the smaller group with severe symptoms the lesions are "latent". only because deep-seated. Even if no gravity should be manifested in' the symptoms, the possibility of grave lesions demands for safety a dorsal percussion, as this almost invariably yields at least some minor indications not otherwise to be got. "Central " or " anterior" lesions may not be latent to an abdominal examination when they are extensive. In that event their manifest importance calls for the most complete examination available, in the light of our illustrative cases of an unsuspected backward extension, not otherwise to be diagnosed except by searching exploration on the operating table.

Lastly, the post-operative examination furnishes evidence as to the results of surgical interference. In the instance of Fig. 5 a dorsal examination, had it been undertaken two or three days after the operation, might have explained the persistence of the pyrexial symptoms. Similarly at a later date in other cases it has yielded information which might have been of clinical use. Any remnants of an abnormal dullness may therefore be worth noting for practical purposes; and they can only be detected by the dorsal method.

REFERENCER

1 The Appendicitis Dilemma, and the Pre-operative Diagnosis BRITISH MEDICAL JodRNAL, June 15th, 1912, p. 1357. 2 The Clinica Uses of Dorsal Percussion, etc., BRITI8H MEDrCAL JouRNAI, 1899, ii 1899, ii, 261 . On Dorsal Percussion of the Thorax and Btomach, and a New Stomach Sign, Proc. Roy. Soc. Med., July, 1910.

\section{THEORIES WITH REGARD TO SECONDARY GROWTHS IN CARCINOMA OF THE BREAST.*}

BX MAY THORNE, F.R.C.S.I.

THE after-history of cases of carcinoma of the breast shows great variety in the length of life accorded to the patient; and the occurrence of secondary nodules in the chest wall, or metastases in distant parts of the body, are still so common that it may be of interest to give a short account of some of the theories that have been held from time to time with regard to the secondary growths of carcinoma of the breast, and to briefly describe some of the operations that have been undertaken for the relief of this condition.

The earliest records speak of the operation as being complete. It consisted apparently in slicing off the entire breast and of freely applying the cautery to the exposed surface of the chest wall. One can imagine that in preanaesthetic days this operation was only undertaken in cases that were considerably advanced, and that to avoid the distress of a large, foul, discharging ulcer a patient here and there might be willing to undergo this ordeal, but one cannot think that many cases would be submitted to an operation of so great severity for what was for a considerable time at least a local and not necessarily painful disease. Many patients doubtless died from metastases long before the primary growth was more than a large, hard lump in the breast. The form of operation undertaken in the earlier years of the nineteenth century was a kind of revulsion from the old and complete method, and consisted in merely excising the prominent portion of the breast in which the tumour occurred, together with the skin adherent to it. It was not to be wondered at that the operation was performed in this very inadequate method, for before the days of growing pathological knowledge carcinoma of the breast was believed to be evidence of constitutional disease, and therefore incurable at whatever stage the operation was undertaken and whatever kind of operation was adopted. Hardly any surgeon dared open the azilla to even shell out large and hard glands because suppuration almost invariably followed the opening up of the loose tissues of the part.

In the early Sixties Moore apparently realized that cancer of the breast might be a local disease at its commencement, and Shield, writing in 1898, says:

Moore correctly estimated the method of the spread of disease, and actually described the complete operation now in vogue, an operation we have so largely adopted from foreign recommendations.

${ }^{*}$ Read before the Association of Registered Medical Women, November 5th, 1912 .
Every one interested in the pathological and eperative conditions of carcinoma of the breast-for the tron run absolutely side by side-should read Sir Watson Cheyne's Lettsomian lecture delivered in 1896, and learn from him how necessarily restricted the operation for this condition was before Lister's introduction of antiseptic methods in the late Sixties. After the introduction of antiseptics Lister himself dared, not only to amputate the breast, but stripped off the pectoral fascia, and opened the axilla in every case and took away the glands and fat of that region.

The time had now come when the inseparable trioanaesthetics, antiseptics, and pathology-began to exercise a vast influence on operations of all kinds. Still, surgeons as a whole liung back for some time from extensive operations on the breast, because the pathology that was then currently accepted did not offer a happy prognosis and patients camo often at so late a stage of the disease that operations were not indicated.

The pathology of the spread of carcinoma of the breast at that time was that of the embolic theory-that is, that cancer cells were carried by the blood stream from the primary growth to distant parts, where the cells were deposited and grew and multiplied, and gave rise to tumour in all respects identical with that of the primary growth. This theory was very reasonable, and was believed to be proved to the hilt over and over again, not only in cases of carcinoma of the breast but in cancer occurring in all parts of the body. Thus a columnarcelled carcinoma of the rectum was found to be exactly reproduced in the liver, and what so reasonable as to suppose that this secondary growth was a direct implantation through the inferior or middle haemorrhoidal veins and the portal circulation to the liver? In cases of metastatic deposit in bone the growth was said so frequently to occupy the position of entry of the nutrient artery of the femur and humerus, the two long bones in which meta stases usually occur, that again the embolic theory of infection by way of the blood stream scemed to be proved.

It had been observed by every one that the glands in the axilla were almost invariably enlarged in cases of cancer of the breast, and the local spread of the disease by way of the lymphatics was known to occur. But the cancer cells which gave rise to metastatic growths were believed to be carried by the blood stream. Stephen Paget, in a most interesting paper in the Lancet of March 23rd, 1889, enters fully into the occurrence of secondary growths, and raises the question as to what determines their distribution. Paget very clearly points out that if the embolic theory is to be held then one must think that emboli will be impartially distributed to all the organs and that the lungs ought to be the most frequent seats of secondary growths; but on careful examination of records of post-mortem cases he found that this was not so. He found in the records of 735 post-mortem examinations on cases of cancer of the breast, that in about 70 cascs only were deposits found in the lungs, and of these, he says, it is impossible to be sure whether some of these growths-unlike deposits in distant organs-were not due to direct extension from the primary growth. As regards the liver, he found that out of this same set of cases 241 of the 735 had secondary growths in the liver, while only 17 had secondary deposits in the spleen, an organ which, if the simple theory of embolism carried by the blood stream is to be credited, ought, he says, to show as much involvement as the liver, since the splenic artery is, if anything, larger than the hepatic artery. But Paget found that in cancer of the uterus the liver again showed the same character to become the seat of secondary disease, for in 244 post-mortem records of cases of cancer of the uterus the liver was involved in 35 cases, the lungs in 8 , and the spleen in 1. Adding these numbers together, he found that secondary growths were found in the liver in 276 cases, in the lungs in 78 cases, while the spleen was only involved in 18 cases. Paget was therefore forced to the conclusion that certain organs have a predisposition to become the seats of secondary growths. Speaking of the deposits in bones, Paget not only gives the reports of cases that have been recorded by other observers, but gives some post-mortem reports of cases who died of breast cancer, on whom an examination had been held at Middlesex Hospital, and gives his conclusions of the predis. position of certain bones to be the sites of secondary 
growths in the following words: "It seems certain that it is not a matter of chance what bone shall be attacked in secondary growths. Who has ever seen the bones of the hands or feet attacked by secondary cancer? Out of 650 necropsies in cases of cancer of the breast which give full details as to the distribution of secondary growths, there is not a single case where the hands or feet were affected, not one of disease of the radius, ulna or fibula, and only one of the tibia. In contrast to this, the femur was affected either by spontaneous fracture or by a distinct deposit of cancer 18 times, the humerus 10, and the cranium 36. The evidence seems to me irresistible that in cancer of the breast the bones suffer in a special way, which cannot be explained by any theory of embolism alone. Some bones suffer more than others; the disease has its seats of election."

The idea suggested by $\mathrm{Mr}$. Paget, namely, that cancer cells carried by the blood stream have a selective power in respect of the part to be attacked, was original, and seemed upheld by the figures he brought forward. Some observers found this theory difficult to accept, but the very difficulty has doubtless been the means of making others investigate the spread of cancer, and to try and find channels for the dissemination of secondary growths which scem more convincing.

Stiles, of Edinburgh, writing in the Britisir Medical Jourval of June 17th, 1899, says that the anatomical facts regarding the breast which were fully recognized by such famous anatomists as Sir Astley Cooper and Henle, namely, that the breast tissue of ten occupies a much wider area than might be supposed, combined with tapering off of its peripheral processes, make it extremely difficult for a surgeon to be always certain that the whole of the breast has been removed, and brings forward evidence to show that in some so-called recurrent growths there is abundant evidence to show that porticns of the breast tissue had been left behind, and that the recurrence was really the continued growth of the disease in parts affected before the first operation was performed. Stiles, by his method of staining with nitric acid, was able to demonstrate the spread of cancer in the tissues in a more graphic way than had been previously accomplished. He also rcfers to the invasion of veins by cancer cells, and quotes Goldmann's work to show that the chronic inflammatory condition set up by the presence of cancer cells in the blood prevents a more general invasion of the blood stream. He thinks that more rarely the arteries become invaded, and says, "It is possible that the sudden formation and cxtensive distribution of lenticular disseminations in the slin may in some instances be due to arterial embolism."

Sir Watson Cheyne gives a most interesting table of percentages of recurrent growths in patients who were operated on by various surgeons. These percentages of recurrences vary from 85 per cent. in Billroth's cases down a descending scale of recurrences till we come to Halsted's 22 per cent. and Cheyne's 18 per cent. When the methods of operation of these two surgeons-Halsted and Cheyne-are compared by Sampson Handley, he finds that while Cheyne undermines his skin flaps, Halsted carried his incision " at once and everywhere through the fat." The recurrences in the shin surrounding the site of operation in Halsted's cases was 16 per cont.; in Cheyne's 6.5 per cent.

Sir Watson Cheyne, in reviewing his cases, says that intcrnal metastatic deposits are apparently more frequen ${ }^{t}$ now than formerly, due, no doubt, to the fact that patients escape local recurrence and live longer, and that thus the internal deposits have time to grow and attract attention.

He also draws attention to the fact that probably many cases of recurrence are due to local infection of the wound at the time of operation by cancer cells which escape from the tumour and lymphatics in the neighbourhood of the tumour, and quotes a case of his orn where he had removed an epithelioma of the tongue. The patient came back with enlargement of glands, which were cystic, from the degeneration of rapidly growing cancer cells. Cheyne thought it worth while to remove them, and did an extensive operation. Unfortunately on one side, while the mass was being taken away a eyst burst, and the fluid, containing flakes of epithelium, poured over the wound. He washed it as thoroughly as he could, but although the one side healed perfectly, the other, where the accident occurred, became brawny and thick all over; diffuse epitheliomatous infiltration of the whole wound followed, and he felt, . no doubt, that the groups of epithelial cells which had escaped grew in the parts of the wound in which they were deposited. $\mathrm{He}$ says also that from a study of the recurrences after the modern operation he has come to the conclusion (1) that cancer in its early stage in a healthy body grows extremely slowly, and that it is only in the later stages, when the resistance of the body is broken down, that the more rapid growth occurs, and (2) that the extensive modern operation (1904) in some way or other exerts an inhibitory growth on cancer cells which are left behind in the vicinity. In some instances, howerer, it appears as if the cancer cells must have lain dormant for a time after the operation. As a result of extensive operation lymph channels arc widely removed, the lymph flow is arrested or slowed through the part, and thus the distribution and nutrition of any cancer cells left behind may bo much interfered with.

Mr. Sampson Handlcy, in his illuminating researches on cancer of the breast, quotes Goldmann's and Schmidt's work to show the degeneration which cancer cells undergo in the blood stream duc to the inflammatory reaction set up by their presence, and thinks that the spread of cancer is due to the permeation of lymphatics by cancer cells.

Taking the primary growth as the centro of a circle, he describes infection as being independent of transport by either blood or lymph stream, and thinks that growti along the lymphatics is the method that occurs. When cancer cells invade a lymphatic and multiply they distend the lymphatic in which they are growing and set up a slight inflammatory reaction round it. After a time the lymphatic becomes distended and bursts. The cancer cells are now free and might grow, one would think, but evidence seems to show that the inflammatory process set up by the rupture intensifies the previous perilymplatic inflammatory process that was present, and a fibrous capsulo forms which shrinlss and strangles the remaining cancer calls. Ultimately the lymphatic itself is replaced by a slight cord of fibrous tissue in which no cancer cells aro seen.

The cancer cells in a distended lymphatic are so pressed upon that they become degenerate, and when freed are ncapable of growtl.

Mr. Sampson Handley points out that, as a curative process, perilymphatic tibrosis is defectire. It does not follow permeation quickly enough to overtake the microscopic growing edge where permeation is just beginning, and also the contraction due to the perilymphatic fibrosis tends to force cancer cells into the smaller lymphatics, which, on account of their higher resistance, have litherto escaped invasion. Passing along these tiny vesscls, tho cancer cells reach and permeate the lymphatic capillarics from which these resscls rise. The walls of these capillaries consist of endothelium only, and are unfitted to bear pressure from the growing cancer cells. Before an adequate inflammatory reaction can ensuc the canccr colls rupture the lymplatic capillaries and invade the surround. ing tissues. If, therefore, living cancer cells reach tho periphery of the lymphatic system, they are able to originate metastases. These may seem to be discretc and separate masses, since the lymphatics along which they have travelled may have been destroyed by perilymphatic fibrosis, but Mr. Sampson Handley claims to have observed that they have originally started from the primary growth.

Mr. Handley, describing the spread of cancer in tho parietes, says it occurs by the permeation of the lymphatic system like the spread of an invisible annular ringworm. "The growing edge extends like a ripple in a wider and wider circle, within whose circumference healing processes take place, so that the area of permeation at any one time is not a disc but a ring. The spread of cancer in the parietal tissues is, in fact, as truly a serpiginons process as the most typical tertiary syphilide. But in the case of cancer the spreading edge is invisible, and; moreover, the advancing microscopic growing edge of a cancer, owing to the failure at isolated points of the defensive process of perilymphatic fibrosis, may leave in its track here and there isolated secondary foci, which give rise to microscopic metastases. Such nodules, in spite of their apparent isolation, arise in continuity with the primary growth, but perilymphatic fibrosis has destroyed the 
permeated lymphatics which formed the lines of com. munication."

The embolic theory of bone infection by the blood stream deemed the entry of the nutrient artery to be the sites of spontaneous fracture or growth.

If the humerus and femur are invaded from the lymphatic plexus of the deep fascia, as Mr. Handley believes, the first attack, he says, should be directed on that point at which the bone lies nearest to the deep fascial lymphatics, and therefore on that point at which the bone comes nearest to the cutaneous surface. Moreover, where the bone is provided with two or more subcutaneous areas, the seat of the first attack, according to the view of centrifugal spread, must be that area which is nearest to the trunk. On this hypothesis the point of invasion should be, and Mr. Handley says is, in the femur, the base of the great trochanter, and the adjoining part of the linea aspera. The point of invasion of the humerus should be, and actually is, relatively much lower down, at the deltoid insertion, since the whole of the upper half of the humerus is well clothed with muscles.

Mr. S. Paget asks, "Who has ever seen the bones of the hands or feet attacked by secondary cancer?" Mr. Handley's answer to this is that no patient lives long enough for centrifugal invasion to reach the distant parts.

Mr. Handley points out that the anatomy of the epigastric region strongly suggests the likelihood of the mode of invasion of the abdominal cavity. According to Stiles, the lower and inner margin of the breast lies over the sixth costal cartilage; that is to say, this part of the mammary circumference is only about an inch from the interspace between the ensiform cartilage and the seventh costal cartilage. Therefore, as soon as parietal permeation has extended little more than an inch beyond the edge of the breast the cancerous lymphatics of the deep fascia are no longer separated from the subserous fat (subperitoneal or subpleural) by a bony cage covered by thick muscles, but simply by a single layer of fibrous tissue traversed by lymphatics. At the tip of the ensiform cartilage the transversalis fascia is hardly recognizable as a distinct layer, and the parietal lymphatic plexus is separated from the subperitoneal fat simply by the linea alba. It is not surprising if through this obviously weak spot cancer frequently reaches the peritoneum before it has succeeded in reaching the pleura, even at points directly subjacent to the primary focus.

Before any operation for the removal of cancer of the breast is undertaken, Mr. Handley advises that a careful examination of the epigastric region should be made to see if there is any tenderness or pain there. The presence of tenderness or pain should raise the suspicion that epigastric invasion had already occurred, and in such cases the liver should be carefully palpated when the patient is under the anaesthetic before the breast is removed, and he goes on to say that it must never be forgotten that the first sign of epigastric invasion may be found not in the epigastric region, but in the pelvis from the gravitation of cancerous particles into it; a vaginal and rectal examination should, he thinks, be made prior to operation.

In operating for removal of breast cancer Mr. Handley strongly advises that the site of the growth be made the centre of a circle from which the deep fascia is to be removed. The skin flaps should be raised till a circle 10 to 12 in. in diameter with the primary growth for its centre is exposed. The exact anatomical limits of this dissection will, of course, vary with the situation of the growth in the breast. An annular incision, marking out the 10-in. circle of deep fascia to be removed, is carried down to the muscles through the deeper subcutaneous fat close to the base of the skin flaps.

In the lower part exposed by this wide raising of the skin flaps the anterior layer of the rectus sheath on both sides of the middle line slould be raised up and removed with the deep fascia, for it is specially in this region that infection of the peritoneal cavity may occur. After dividing the pectoral muscles, exposing the costo-coracoid membrane, and clearing the apex of the axilla, the whole mass is turned outwards, and where the digitations of serratus magnus lie in contact with the deep surface of the breast they should be removed together with a superficial layer of the digitations of external oblique.

The theory of infection, even of distal parts, by way of the lymphatics, commends itself strongly, but the question still is whether this is the only source of infection. Sir George Beatson of Glasgow, who has done much and good work on breast cancer, pays a tribute to Sampson Handley for the work he has done in outlining the limits of the lymphatic system and its distribution, but does not agree with him in his permeation theory, and feels there is more than that needed to explain all that is found, and takes the view that pressure dissemination represents more clearly what takes place.

Mr. G. L. Cheatle, in several interesting papers, drarvs attention to the fact that there seems to be a certain rela. tion between nerve supply and the growth of cancer, and that there seems a greater tendency for the disease to spread along the area of the particular nerve distri. bution in which it first occurred rather than inde. pendently into neighbouring areas. Mr. Cheatle also states that he has been able to demonstrate that in. flammatory changes occurred in two post-mortem cases in the spinal ganglion, on the cutaneous distribution of which the cancer had begun, whilst the ganglia into whose cutaneous distribution the cancer had spread showed the changes of degeneration which had been noted both by Lugaro and himself, and points out that in the two cases described the cancer began on parts of the skin where nerves become cutaneous. If the lesions in the ganglia were secondary to the lesions of the skin, then Mr. Cheatle thinks that there would also have been secondary inflam. matory changes in all the ganglia whose peripheral branches were involved in the lesion, but he found that this was not the case, although these particular branches had been involved for many years. Mr. Cheatle puts three pertinent questions which certainly ought to be borne in mind in investigating cancer, namely:

1. Is the inflammatory change within the posterior spinal root ganglia in any way connected with origin or spread of cancer ?

2. If it is, did it exist before the cancer began? and hence had it anything to do with the genesis or point of incident?

3. If it occurred secondarily to the cancer, had its presence anything to do with the spread of that disease?

The theory of the spread of breast cancer brought forward by Mr. Handley offers a much more hopeful prognosis in early cases than has hitherto been possible, but still Sir Watson Cheyne's advice given some years back, namely, that in the first operation lies the patient's only chance, and that it must therefore be done with the greatest thoroughness, however limited the disease may be at the time of operation, is as true now as ever it was.

\section{Bibliography}

Williams, Diseases of Breast. Marmaduke Shield, Disea ses of the Breast. S. Paget, Lancet, 1889. Watson Cheyne, Lancet, 1904. Lectures, 1896. MEDIGAL JodRNAL, 1899, Cheyne, Lettsomian C. Lenthal Cheatle, BRITISH MEDICAL JOURSAL, 1903 and 1907.

\section{FOREIGN BODY IN THE ABDOMINAL CAVITY.}

BY

LLEWELLYN B. GREEN, M.R.C.S., L.R.C.P., SURGEON TO THE ROSS COTTAGE HOSPITAL.

THE following case appears to me to be of more than ordinary interest :

A married woman, multipara, aged 33 , came to me on September 5th, 1912, in great trouble. She told me that on September 2nd, as her period had not come on at the usual time she had endeavoured to bring it on by introducing the end of a bone crochet hook into the uterus, of a bone crochet hook into the uterus, a plan which she had from her fingers and disappeared, and she had been unable to find it since, although she had sought for it with a "marrow spoon." There had been some slight haemorrhage, but not so much as with an ordinary period.

When I saw her she complained of some pain in the lowe part of the abdomen, which had been increased by the jolting of the spring cart in which she had come four miles to see me. The pulse was 64 ; temperature $98.4^{\circ}$; bowels open.

On vaginal examination the os was just open enough to admit the tip of the finger, which on withdrawal was slightly admit stained. There was no marked tenderness, nor any sign of crochet hook. 